\title{
Assessing Spread and Impacts of Non-native Plants from Highway Corridors in the Northwest Territories (NWT), Canada
}

\author{
by Claire L. Singer
}

\section{INTRODUCTION}

$\mathrm{S}$ PECIES INVASIONS ARE RECOGNIZED AS ONE of the leading threats to biodiversity globally (Lassuy and Lewis, 2013) and have been associated with declines in native species and changes in ecosystem function, disturbance regimes, species community composition and structure, and species interactions (Lodge and SchraderFrechette, 2003; Vila and Ibanez, 2011). Invasions are often strongly associated with human disturbances and increased propagule pressure (i.e., the number of introduction events and number of individuals per event) (Vila and Ibanez, 2011; Langor et al., 2014). Thus, transportation corridors like roads, which experience ongoing disturbance as well as potentially large numbers of unintentional introductions of non-native plant propagules due to vehicular traffic, are often key pathways for the introduction and spread of non-native species into remote areas. Additionally, spread of non-native plants away from these anthropogenicallydisturbed corridors into natural areas, including into natural disturbances (e.g., riverbanks, forest fire burns) in particular, is increasingly being documented (Carlson and Shephard, 2007; Chown et al., 2012; Spellman et al., 2014; Aronson et al., 2017).

In considering establishment, spread, and impact of non-native plants, it is important to distinguish between the different selection factors operating at each stage of the invasion process (With, 2001; Lockwood et al., 2013). For example, while roadside disturbance typically selects for annual plants with low competitive abilities and full sun requirements, non-native plants able to move from the roadside into adjacent natural areas are more typically shade and moisture tolerant species with perennial life cycles (McDougall et al., 2018). That is to say, life history characteristics can inform the likelihood of establishment, spread, and impact by non-native species (Lockwood et al., 2013). The traits of the receiving environment similarly inform invasion success (Alpert et al., 2000; Van Riper et al., 2010; Pysek et al., 2012).

Although considerable research has examined how disturbances, propagule pressure, and traits affect the introduction and spread of non-native species, few studies have investigated these questions in Canada's boreal forest. Given the context-dependency of non-native species establishment, spread, and impact demonstrated elsewhere (i.e., typically species- and habitat-specific) (Van Riper et al., 2010; Pysek et al., 2012), research focused in Canada's boreal forest will provide context-specific information that may assist with projecting invasions and ecological responses in this region (Rew et al., 2020). This is particularly relevant for biodiversity managers as climate change intensifies in this region, which is likely to increase the number of introductions of non-native species and facilitate spread into newly available habitat (Lassuy and Lewis, 2013; IPCC, 2014; Rew et al., 2020). The magnitude of the projected climate warming along with increasing human activity, naturally low species diversity, and an active natural disturbance regime means that northern regions may be quite strongly vulnerable to species invasions (Lassuy and Lewis, 2013; CAFF and PAME, 2017; Rew et al., 2020).

My research focuses on assessing non-native plant spread at sampling sites along roadsides in southwestern Northwest Territories (NWT), Canada and impacts to native plant and soil-associated arthropod communities. This study represents an opportunity to determine whether spread and impact differ among localized habitats in the boreal forest, and whether they are consistent with invasion ecology hypotheses developed based largely on research in other regions.

Non-native plant presence has previously been confirmed along all highways in the NWT (Oldham and Delisle-Oldham, 2017); however, spread of non-native plants away from these highway introduction sites has not been measured to date. My research assesses the degree of non-native plant spread into burns and rivers that adjoin the highways and across different habitat types within the study area (level IV ecoregions are being used as a proxy for habitat type; Ecosystem Classification Group, 2008, 2009). Results are being compared against spread into undisturbed areas that adjoin the highways in similar habitat types; these undisturbed areas provide a control against which to assess the relative invasibility of natural disturbances versus intact natural areas. The identification of invaded areas during this work will inform site selection for a subsequent impact study, which will assess the impact 
of non-native plants on native plant and soil-associated arthropod communities. Finally, a trait-based assessment of the risk to the NWT of new plants establishing will be completed.

\section{RESEARCH APPROACH}

Spread of non-native plants into burns, riverbanks, and undisturbed areas adjacent to highways will be assessed using one square meter plots situated at set distances along transects that run perpendicular to the road corridor. Transects into undisturbed areas are paired with burn and river transects (i.e., within the same habitat type and with the same dominant stand type), with the edge oriented in the same direction as the burn or river transect it is being paired with, and placed a minimum of $250 \mathrm{~m}$ away from these disturbances to minimize edge effects (Vila and Ibanez, 2011; Harper et al., 2015).

The number of plots per transect ranges from a minimum of three to a maximum of 16 plots per transect. The first three plots will include two plots within the verge of the road and one immediately within the forest edge (edge plot). Where non-native plant presence is detected at any of these three plots, additional plots at defined distances from the edge plot are added to the transect until two consecutive plots contain no non-native plants (Rew and Maxwell, 2006; Sumners and Archibold, 2007) in order to define the limit of spread.

Non-native and native plant inventories and BraunBlanquet cover estimates will be completed within each plot. Ditch width and distance from the road edge will be measured. Dominance (total non-native/native cover), which is a useful metric for understanding response thresholds (Litt et al., 2014), will be estimated for each plot (LaPaix et al., 2012). Hierarchical models will be used to assess whether spread differs by disturbance type (i.e., comparison among burns, rivers, and undisturbed sites), habitat, or species. Native and non-native plants will be defined based on species classifications in the General Status Ranks of NWT Species 2016 (Working Group for General Status Ranks of the NWT, 2016), with taxonomy updated where necessary in accordance with VASCAN (Database of Vascular Plants of Canada).

Preliminary work to test this sampling protocol was completed in summer 2021 (Figs. 1 and 2). Full spread sampling is scheduled to begin in summer 2022. The work of 2021 permitted an assessment of the feasibility of this protocol in the field and will inform modifications for sampling along rivers prior to the 2022 field season. Specifically, while the sampling protocol appeared reasonable for burns and associated paired sites, it became clear in the field that sampling rivers by walking the riverbank from the nearest point where it adjoins the highway would be logistically challenging-dense vegetation at the shoreline often made access exceedingly difficult. Further, perhaps reflecting the dense growth along these highway-adjoining riverbanks, there was little evidence of non-native plants at these sites. Anecdotal reports of non-native plant spread along river corridors in the NWT (Larter pers. comm., 2020; Carrière pers. comm. 2021) suggest that boat-based surveys will be more effective, with a focus on islands and gravel bars; areas where Melilotus spp. (white and yellow sweet clover) and Tripleurospermum inodorum (scentless chamomile) are thought to be spreading.

In addition to these scientific methods of data collection, and recognizing the vast history and knowledge of Indigenous peoples in the NWT, the presence, spread, and impact of non-native plants will also be assessed more broadly by collecting Indigenous knowledge. This work will be completed in cooperation with a working group currently coordinating a territory-wide Indigenous knowledge study on Vaccinium vitis-idaea (lowbush cranberries, rock cranberries, lingonberries). Although focused on cranberries, abiotic and biotic factors that may be influencing their status in the territory (e.g., climate, new plant introductions, distribution shifts) will also be captured and as such, this work may shed light on non-native plant species across the NWT as well as changes to native plant communities. The working group is currently defining detailed research plans and methods to ensure schedules and methods are appropriate and respectful, and knowledge holders are able to meaningfully direct research plans. This work has, unfortunately, been delayed and modified several times as a result of the Covid-19 pandemic, but continues at a slower pace and in deference to pandemic safety precautions.

Importantly, not all introduced plants are expected to have negative ecological or economic impacts (Lockwood et al., 2013). In determining management priorities, it is important to understand whether, and if so, which species are affecting native species communities. As such, a second objective of my research is to assess the impact of nonnative plants on native plant and soil-associated arthropod communities.

Invaded sites in burns, rivers, and undisturbed areas will be paired with similar uninvaded sites to complete this assessment (Zubek et al., 2016; Kent et al., 2018). Sampling at each paired site will occur on a single one square meter plot. A vegetation inventory will be completed for each plot along with data collection for soil $\mathrm{pH}$, moisture and temperature, and soil-associated arthropod species diversity (Lamb et al., 2011; Barney et al., 2013). To sample soilassociated arthropod diversity, a combination of pan traps and soil-sifting will be utilized (Pentinsaari et al., 2020). Hierarchical models will be used to assess differences in species richness and abundance between paired sites.

Finally, considering plant traits associated with establishment, spread, and impact, a third objective of this research is to assess the risk of plants in neighbouring southern jurisdictions being introduced to and impacting NWT ecosystems. There are a variety of models that have been developed to project the likelihood of dispersal, 


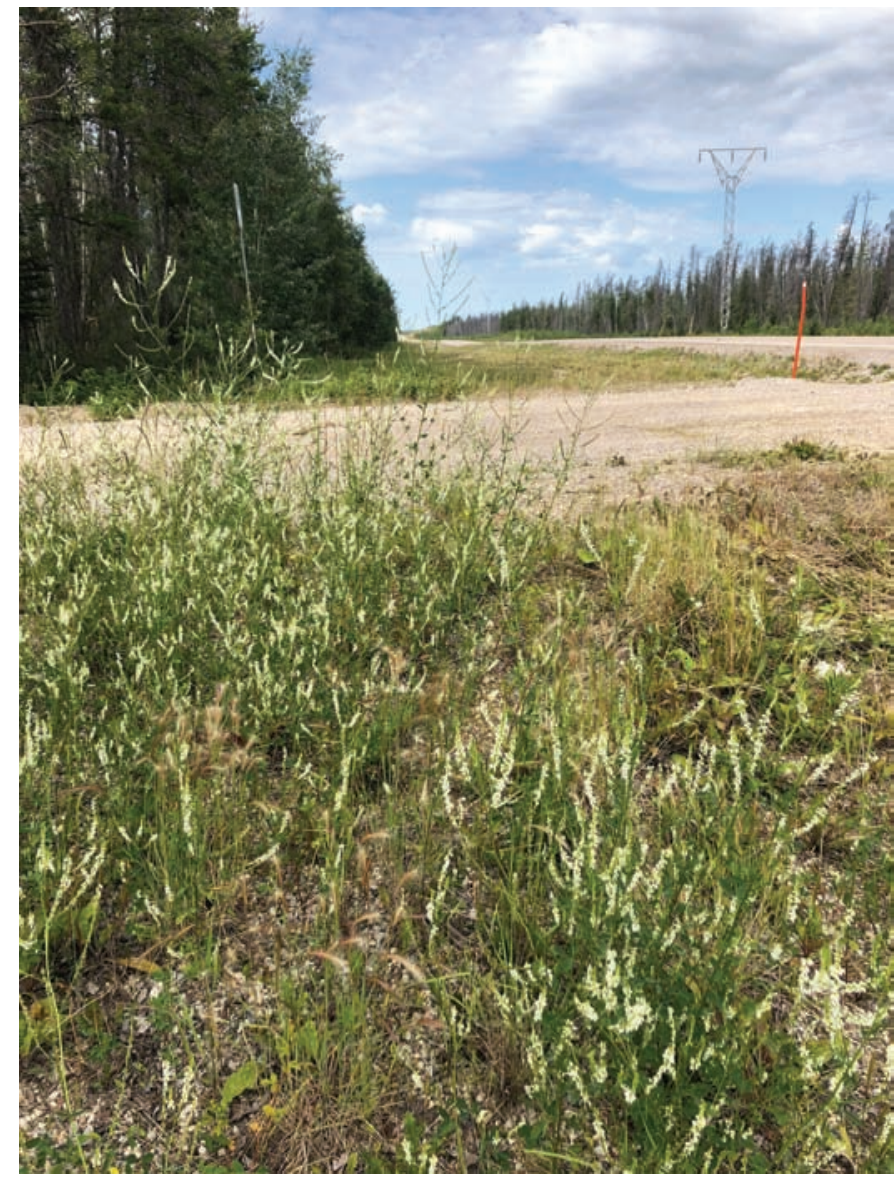

Fig. 1. Melilotus albus (white sweet clover) growing along Highway 3 in the NWT (Photo: C. Singer).

establishment, or impact of non-native species (Dickey et al., 2010; Thiele et al., 2010; Alexander et al., 2018; Chai et al., 2016; Chapman et al., 2019; Fournier et al., 2019). These models are often trait-based (Fournier et al., 2019) or habitat suitability models (Thiele et al., 2010), or a combination of both (Chai et al., 2016; Chapman et al., 2019). Although there are limitations to the inputs these models can currently consider, including the development of no-analog climates, use of realized rather than fundamental niches, abiotic or biotic climatic buffers (e.g., topography, shading), development of novel biotic interactions, co-stressors (e.g., anthropogenic landscape change), and residence time (Williams and Jackson, 2007; Wilson et al., 2007), they can nonetheless be valuable in projecting and prioritizing management responses to non-native species (Bonebrake et al., 2018).

This assessment will include completion of a trait-based risk assessment for the NWT using the methods developed by Carlson et al. (2008). This model considers current and potential habitat suitability alongside a species' ecological impact, invasive characteristics, dispersal capacity, and control feasibility. It also addresses both the likelihood of establishment and potential impact and, importantly, allows for missing trait information. Scores provide a ranking linked to management priority.

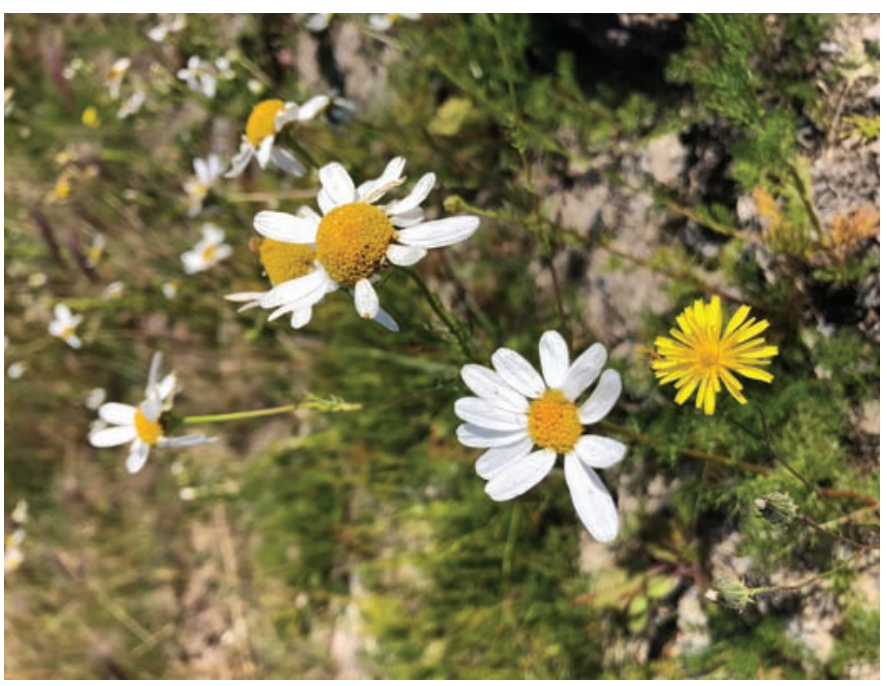

Fig. 2. Tripleurospermum inodorum (scentless chamomile) growing alongside Highway 3 in the NWT (Photo: C. Singer).

\section{SIGNIFICANCE}

One hundred and forty non-native plant species have been documented in the NWT to date (Oldham and DelisleOldham, 2017). Approximately 900 other vascular plant species have been identified as possible future risks to the territory (Snyder and Anions, 2008). These lists will be analyzed carefully based on common invasibility and impact factors like size of home range and dispersal capacity (Alpert et al., 2000) to narrow the selection down to a subset of species, which will be the subjects of this risk assessment.

The magnitude of projected climate change in high latitude regions, particularly if coupled with increasing human disturbance, suggests that these areas will be subject to substantial change over the course of the 21st century (SNAP, 2012; Rew et al., 2020), such that maintenance of historical species' assemblages is unlikely in the long-term (Rew et al., 2020). These trends may challenge biodiversity managers (Bonebrake et al., 2018), for instance, by altering habitat conditions or rendering management objectives based on a return to historical baseline conditions less achievable. Building an understanding of how native plant and arthropod communities are and might respond to non-native species invasions in the future is integral to long-term biodiversity conservation success and proactive management (Root et al., 2003; Rew et al., 2020; Stralberg et al., 2020).

Relatively little research has been conducted on this topic in the Canadian boreal forest to date, particularly within the NWT, and given context- and species-specific responses in native species communities to environmental change and species invasions documented elsewhere (Van Riper et al., 2010; Pysek et al., 2012), projecting responses in this region will be difficult without additional research (Rew et al., 2020). This research represents the first broad-scale study on spread and impacts of non-native plants in the NWT. 


\section{ACKNOWLEDGEMENTS}

I am honoured to be the Arctic Institute of North America's 2021 recipient of the Lorraine Allison Memorial Scholarship. I would like to thank Rob Gau, Heather Sayine-Crawford, Dr. Brett Elkin, Dr. Erin Kelly (Government of the Northwest Territories [GNWT]), Jody Pellissey (Executive Director, Wek'èezhìı Renewable Resources Board), and Dr. Deborah Simmons (Executive Director, Sahtú Renewable Resources Board) for the support they continue to offer me in the pursuit of my education, and Johanna Stewart (Wildlife Technician, Invasive Species, GNWT) and my parents (Garry and Lesley Singer) for their field assistance.

Funding for this research and my program of study was provided by the Northern Scientific Training Program, the Department of Environment and Natural Resources, GNWT, and NSERC (Discovery Grant to E. Cameron). Research this year was undertaken per a Scientific Research License (\#16861) and Forest Research Permit (RL202101) issued by the Aurora Research Institute and Forest Management Division, Department of Environment and Natural Resources, Government of the Northwest Territories, respectively.

Finally, I would like to my supervisor, Dr. Erin Cameron, for the support, guidance, and patience she has shown to me, particularly given the number of years it has been since I was in an academic environment, and committee members Dr. Karen Harper and Dr. Kevin Vessey for their valuable advice.

\section{REFERENCES}

Alexander, J.M., Chalmandrier, L., Lenoir, J., Burgess, T.I., Essl, F., Haider, S., Kueffer, C., et al. 2018. Lags in the response of mountain plant communities to climate change. Global Change Biology 24(2): 563-579. https://doi.org/10.1111/gcb.13976

Alpert, P., Bone, E., and Holzapfel, C. 2000. Invasiveness, invasibility and the role of environmental stress in the spread of non-native plants. Perspectives in Plant Ecology, Evolution and Systematics 3(1):52-66.

https://doi.org/10.1078/1433-8319-00004

Aronson, M.F.J., Patel, M.V., O’Neill, K.M., and Ehrenfeld, J.G. 2017. Urban riparian systems function as corridors for both native and invasive plant species. Biological Invasions 19(12): $3645-3657$. https://doi.org/10.1007/s10530-017-1583-1

Barney, J.N., Tekiela, D.R., Dollete, E.S., and Tomasek, B.J. 2013. What is the "real" impact of invasive plant species? Frontiers in Ecology and the Environment 11(6):322-329. https://doi.org/10.1890/120120

Bonebrake, T.C., Brown, C.J., Bell, J.D., Blanchard, J.L., Chauvenet, A., Champion, C., Chen, I.-C., et al. 2018. Managing consequences of climate-driven species redistribution requires integration of ecology, conservation and social science: Research directions in species redistribution. Biological Reviews 93(1):284-305. https://doi.org/10.1111/brv.12344
CAFF PAME (Conservation of Arctic Flora and Fauna and Protection of the Arctic Marine Environment). 2017. Arctic invasive alien species: Strategy and action plan 2017. Akureyri, Iceland: Conservation of Arctic Flora and Fauna and Protection of the Arctic Marine Environment.

Carlson, M.L., Lapina, I.V., Shephard, M., Conn, J.S., Densmore, R., Spencer, P., Heys, J., Riley, J., and Nielsen, J. 2008. Invasiveness ranking system for non-native plants of Alaska. R10-TP-143. Anchorage, AK: United States Department of Agriculture, Forest Service Alaska Region.

Carlson, M.L., and Shephard, M. 2007. Is the spread of nonnative plants in Alaska accelerating? In: Harrington, T.B., and Reichard, S.H., eds. Meeting the challenge: Invasive plants in Pacific northwest ecosystems. Portland, OR: United States Department of Agriculture, Forest Service, Pacific Northwest Research Station. $111-127$.

Chai, S.-L., Zhang, J., Nixon, A., and Li, B. 2016. Using risk assessment and habitat suitability models to prioritize invasive species for management in a changing climate. PLoS ONE 11(10): e0165292.

Chapman, D., Pescott, O.L., Roy, H.E., and Tanner, R. 2019. Improving species distribution models for invasive non-native species with biologically informed pseudo-absence selection. Journal of Biogeography 46(5):1029-1040.

https://doi.org/10.1111/jbi.13555

Chown, S.L., Huiskes, A.H.L., Gremmen, N.J.M., Lee, J.E., Terauds, A., Crosbie, K., Frenot, Y., et al. 2012. Continentwide risk assessment for the establishment of nonindigenous species in Antarctica. Proceedings of the National Academy of Sciences 109(13):4938-4943. https://doi.org/10.1073/pnas.1119787109

Dickey, J.W.E., Cuthbert, R.N., South, J., Britton, J.R., Caffrey, J., Chang, X., Crane, K., et al. 2010. On the RIP: Using relative impact potential to assess the ecological impacts of invasive alien species. NeoBiota 55:27-60. https://doi.org/10.3897/neobiota.55.49547

Ecosystem Classification Group. 2008. Ecological regions of the Northwest Territories: Taiga Shield. Yellowknife, NT: Department of Environment and Natural Resources, Government of the Northwest Territories.

https://www.enr.gov.nt.ca/sites/enr/files/wkss_taiga_ shield-2008.pdf

. 2009. Ecological regions of the Northwest Territories:

Taiga Plains. Yellowknife, NT: Department of Environment and Natural Resources, Government of the Northwest Territories. https://www.enr.gov.nt.ca/sites/enr/files/resources/taiga_ plains_ecological_land_classification_report.pdf

Fournier, A., Penone, C., Pennino, M.G., and Courchamp, F. 2019. Predicting future invaders and future invasions. Proceedings of the National Academy of Sciences 116(16):7905-7910. https://doi.org/10.1073/pnas.1803456116

Harper, K.A., Macdonald, S.E., Mayerhofer, M.S., Biswas, S.R., Esseen, P., Hylander, K., Stewart, K.J., et al. 2015. Edge influence on vegetation at natural and anthropogenic edges of boreal forests in Canada and Fennoscandia. Journal of Ecology 103(3):550-562.

https://doi.org/10.1111/1365-2745.12398 
IPCC (Intergovernmental Panel on Climate Change). 2014. Climate change 2014: Synthesis report. Pachauri, R.K., and Meyer, L.A., eds. Contribution of Working Groups I, II, and III to the Fifth Assessment Report of the Intergovernmental Panel on Climate Change. Geneva, Switzerland: IPCC. https://www.ipcc.ch/site/assets/uploads/2018/05/SYR_AR5 FINAL_full_wcover.pdf

Kent, A., Drezner, T.D., and Bello, R. 2018. Climate warming and the arrival of potentially invasive species into boreal forest and tundra in the Hudson Bay Lowlands, Canada. Polar Biology 41(10):2007-2022. https://doi.org/10.1007/s00300-018-2341-2

Lamb, E.G., Han, S., Lanoil, B.D., Henry, G.H.R., Brummell, M.E., Banerjee, S., and Siciliano, S.D. 2011. A High Arctic soil ecosystem resists long-term environmental manipulations: Arctic soil resists environmental change. Global Change Biology 17(10): 3187-3194. https://doi.org/10.1111/j.1365-2486.2011.02431.x

Langor, D.W., Cameron, E.K., MacQuarrie, C.J.K., McBeath, A., McClay, A., Peter, B., Pybus, M., et al. 2014. Non-native species in Canada's boreal zone: Diversity, impacts, and risk. Environmental Reviews 22(4):372-420. https://doi.org/10.1139/er-2013-0083

LaPaix, R., Harper, K., and Freedman, B. 2012. Patterns of exotic plants in relation to anthropogenic edges within urban forest remnants. Applied Vegetation Science 15:525-535. https://doi.org/10.1111/j.1654-109x.2012.01195.x

Lassuy, D.R., and Lewis, P.N. 2013. Invasive species: Humaninduced. In: Arctic biodiversity assessment. Akureyri, Iceland: Conservation of Arctic Flora and Fauna. 558-565. http://www.arcticbiodiversity.is/index.php/the-report/ chapters/invasive-species-human-induced

Litt, A.R., Cord, E.E., Fulbright, T.E., and Schuster, G.L. 2014. Effects of invasive plants on arthropods. Conservation Biology 28(6):1532-1549. https://doi.org/10.1111/cobi.12350

Lockwood, J.L., Hoopes, M.F., and Marchetti, M.P. 2013. Invasion ecology. 2nd ed. West Sussex, UK: Wiley-Blackwell.

Lodge, D.M., and Shrader-Frechette, K. 2003. Nonindigenous species: Ecological explanation, environmental ethics, and public policy. Conservation Biology 17(1):31-37. https://doi.org/10.1046/j.1523-1739.2003.02366.x

McDougall, K.L., Lembrechts, J., Rew, L.J., Haider, S., Cavieres, L.A., Kueffer, C., Milbau, A., et al. 2018. Running off the road: Roadside non-native plants invading mountain vegetation. Biological Invasions 20:3461-3473.

https://doi.org/10.1007/s10530-018-1787-z

Oldham, M.J., and Delisle-Oldham, M. 2017. Report on the 2016 survey of exotic plants along Northwest Territories highways. Yellowknife, NT: Department of Environment and Natural Resources, Government of the Northwest Territories. https:/www.enr.gov.nt.ca/sites/enr/files/resources/report on_the_2016_survey_of_exotic_plants_along_northwest_ territories_h.pdf
Pentinsaari, M., Blagoev, G.A., Hogg, I.D., Levesque-Beaudin, V., Perez, K., Sobel, C.N., Vandenbrink, B., and Borisenko, A. 2020. A DNA barcoding survey of an Arctic arthropod community: Implications for future monitoring. Insects 11(1):46. https://doi.org/10.3390/insects11010046

Pyšek, P., Jarošík, V., Hulme, P.E., Pergl, J., Hejda, M., Schaffner, U., and Vilà, M. 2012. A global assessment of invasive plant impacts on resident species, communities and ecosystems: The interaction of impact measures, invading species' traits and environment. Global Change Biology 18(5):1725-1737. https://doi.org/10.1111/j.1365-2486.2011.02636.x

Rew, L.J., and Maxwell, B.D. 2006. Stratified random sampling method. In: Rew, L.J., and Pokorny, M.L., eds. Inventory and survey methods for nonindigenous plant species. Bozeman, MT: Montana State University Extension. 49-55.

Rew, L.J., McDougall, K.L., Alexander, J.M., Daehler, C.C., Essl, F., Haider, S., Kueffer, C., et al. 2020. Moving up and over: Redistribution of plants in alpine, Arctic, and Antarctic ecosystems under global change. Arctic, Antarctic, and Alpine Research 52(1):651-665.

https://doi.org/10.1080/15230430.2020.1845919

Root, T.L., Price, J.T., Hall, K.R., Schneider, S.H., Rosenzweig, C., and Pounds, J.A. 2003. Fingerprints of global warming on wild animals and plants. Nature 421:57-60.

https://doi.org/10.1038/nature01333

SNAP (Scenarios Network for Arctic Planning). 2012. Predicting future potential climate-biomes for the Yukon, Northwest Territories, and Alaska: A climate-linked cluster analysis approach to analyzing possible ecological refugia and areas of greatest change. Anchorage, AK: Nature Conservancy Canada, Arctic Landscape Conservation Cooperative, US Fish and Wildlife Service, Ducks Unlimited Canada, Government of Canada, and Government of the Northwest Territories.

https://cupdf.com/document/predicting-future-potentialclimate-biomes-for-the-yukon-northwest-territories.html

Snyder, E., and Anions, M. 2008. Pathways analysis of invasive plants and insects in the Northwest Territories. Yellowknife, NWT: Department of Environment and Natural Resources, Government of the Northwest Territories.

https://www.enr.gov.nt.ca/sites/enr/files/reports/report_on_ pathways_analysis_nwt.pdf

Spellman, K.V., Mulder, C.P.H., and Hollingsworth, T.N. 2014. Susceptibility of burned black spruce (Picea mariana) forests to non-native plant invasions in interior Alaska. Biological Invasions 16(9):1879-1895.

https://doi.org/10.1007/s10530-013-0633-6

Sumners, W.H., and Archibold, O.W. 2007. Exotic plant species in the southern boreal forest of Saskatchewan. Forest Ecology and Management 251:156-163.

https://doi.org/10.1016/j.foreco.2007.06.001

Stralberg, D., Arseneault, D., Baltzer, J.L., Barber, Q.E., Bayne, E.M., Boulanger, Y., Brown, C.D., et al. 2020. Climate-change refugia in boreal North America: What, where, and for how long? Frontiers in Ecology and the Environment 18(5):261 - 270. https://doi.org/10.1002/fee.2188 
Thiele, J., Kollmann, J., Markussen, B., and Otte, A. 2010. Impact assessment revisited: Improving the theoretical basis for management of invasive alien species. Biological Invasions 12(7):2025-2035. https://doi.org/10.1007/s10530-009-9605-2

Van Riper, L.C., Larson, D.L., and Larson, J.L. 2010. Nitrogenlimitation and invasive sweetclover impacts vary between two Great Plains plant communities. Biological Invasions 12(8): $2735-2749$. https://doi.org/10.1007/s10530-009-9678-y

Vila, M., and Ibanez, I. 2011. Plant invasions in the landscape. Landscape Ecology 26:461 - 472. https://doi.org/10.1007/s10980-011-9585-3

Williams, J.W., and Jackson, S.T. 2007. Novel climates, no-analog communities, and ecological surprises. Frontiers in Ecology and the Environment 5(9):475-482. https://doi.org/10.1890/070037

Wilson, J.R.U., Richardson, D.M., Rouget, M., Procheş, Ş., Amis, M.A., Henderson, L., and Thuiller, W. 2007. Residence time and potential range: Crucial considerations in modelling plant invasions. Diversity and Distributions 13(1):11-22. https://doi.org/10.1111/j.1366-9516.2006.00302.x
With, K.A. 2002. The landscape ecology of invasive spread. Conservation Biology 16(5):1192-1203. https://doi.org/10.1046/j.1523-1739.2002.01064.x

Working Group on General Status of NWT Species. 2016. NWT species 2016-2020: General status ranks of wild species in the Northwest Territories. Yellowknife, NWT: Department of Environment and Natural Resources, Government of the Northwest Territories.

https://www.nwtspeciesatrisk.ca/sites/enr-species-at-risk/ files/nwtspecies_2016_2020_report_final_w_properties.pdf

Zubek, S., Majewska, M.L., Błaszkowski, J., Stefanowicz, A.M., Nobis, M., and Kapusta, P. 2016. Invasive plants affect arbuscular mycorrhizal fungi abundance and species richness as well as the performance of native plants grown in invaded soils. Biology and Fertility of Soils 52(6):879-893. https://doi.org/10.1007/s00374-016-1127-3

Claire L. Singer is the 2021 recipient of the Lorraine Allison Memorial Scholarship. She is currently a PhD student in the Environmental Sciences Department at Saint Mary's University. Claire.Singer@smu.ca 